\title{
The Poverty of Sexuality
}

The current conceptualization of homosexuality as a condition is a false one... It is interesting to notice that homosexuals themselves welcome and support the notion that homosexuality is a condition. For just as the rigid categorization deters people from drifting into deviancy, so it appears to foreclose on the possibility of drifting back into normality and thus removes the element of anxious choice.

-Mary McIntosh, "The Homosexual Role"

One of the first questions that European gay men asked themselves in Johnny and Justice's neighborhood was something like "Is this African man really gay"? On Internet sites and in person, Africans presented themselves as "gay," but as we have seen, other aspects of their lives seemed (to Europeans) to stand in contradiction with this claim. In all, it was not my impression that African men were much concerned with the question of sexuality.

It is fairly common, as I have already pointed out, in sexual cultures across the world for those who penetrate in male-male 
sex to be thought of as ordinary men. Unlike today, when our current notions of homosexuality mark both partners to a samesex act as deviating from the norm, as little as a century ago, things were different across many areas of the world: only men who were penetrated, orally or anally, were marked as "queer."

Did some similar conceptual sorting, on the part of Africans, facilitate the meeting of gay Europeans and Africans in the ghetto? The answer appears to be no. While most Europeans in Johnny's neighborhood were apparently (mostly) bottoms, this was not universally the case. One German man was said to be a total top. Moreover, two European "bottoms" reported to me that at some point in their relationships, their African lover had asked if they wanted to switch roles (and one had). The sexual versatility of African men seems to have made the question of whether they were really gay beside the point-for their European lovers. One said, "If my friend had been born in Europe, I'm sure he would have been gay. Straight men just don't do what he does."

My information on the intimacies of same-sex sex between Atlantic Africans and Europeans is strikingly paralleled by the account by Nii Ajen (apparently a pseudonym), an African author in Murray and Roscoe's (1998, 133-34) pioneering volume. Let me quote at some length:

Three white European gay males I interviewed who live in West Africa with their boyfriends spoke of their mixed feelings because of their lover's marriage and partial commitment to their relationship. All three of them admitted enjoying sex profoundly with their African men and only wished they could have had them for themselves alone. Interestingly, the three lovers they spoke of were all said to be extremely versatile in their erotic behavior with their male partners and also in their social roles. 
A survey I conducted in London during 1994 of fifteen men born and raised in West Africa who moved to Europe no later than 1990 and who have sex with men regularly provided the following information. They were between the ages of twenty-three and forty. Of the fifteen, four were exclusively homosexual, the other eleven saying they don't mind sleeping with a woman. What was more striking was that two of the eleven said they have problems with sleeping with women, yet cannot think of living without a woman in their life. Also, only two of the fifteen accepted the label "gay." Both were effeminate, exclusively homosexual, and exclusively receptive (that is, "bottoms"). The other thirteen refused the label outright, as they see "gay" as a Western, stigmatized label ... Thirteen of the fifteen also had childhood sexual experiences with friends or schoolmates before puberty. Three of them were anally raped as children. The other ten learned from friends, schoolmates, or caregivers. Eleven are versatile in their sexual roles now. The other two discovered sex long after puberty: one at age twenty-two and the other at age twenty-five. The two who had their first experiences in their twenties said they were exclusively insertive ("tops"). Although they admitted to enjoying same-sex intimacy whenever they have it, these two indicated that they do have moments when they feel bad about going to bed with men.

So what was the "sexuality" of these African men?

It is useful, at this point, to compare sexuality to ethnicity. There are, of course, disagreements among scholars who study ethnicity, but virtually no one would now argue that ethnic "essences" propel behavior. In certain contexts, people can be mobilized under an ethnic banner to carry out various goals, all the way from the formation of communities, to campaigns for liberal rights, to violence and the elimination of others (Donham 2oII). In this way, "ethnicity" provides identity terms that can be taken up by actors themselves, attributed to others in certain contexts, and even embedded in bureaucratic state 
structures. But whatever ethnicity is, it is hardly an essence or a state of being-except to its true believers (and then even they inevitably fail to enact purity).

If a social actor claimed, for example, that he had no choice in some matter, that his deep sense of ethnic identity (say, Zuluness) compelled him toward a certain act, few observers would take this as an adequate explanation. Yet a great many do with respect to sexuality. The inadequacy of doing so is, I take it, the central point of historian Joan Scott's discussion of individual experience as historical evidence: "We need to attend to the historical processes that, through discourse, position subjects and produce their experiences. Experience in this definition then becomes not the origin of our explanation, not the authoritative (because seen or felt) evidence that grounds what is known, but rather that which we seek to explain, that about which knowledge is produced. To think about experience in this way is to historicize it as well as to historicize the identities it produces" (1991, 779-80).

So what if any kind of sex, like any kind of culture, is a potentiality for anyone? What if sex is learned, what if it reflects not only cultural definitions, as the social constructionists have argued now for decades, but also, crucially, subgroup social pressures (see especially Reiss 196r)? The position I am advocating emerges in one of Silvan Tomkins's brilliantly detached discussions of how bodily drives can be consummated:

The drive system has a limited degree of substitutability of consummatory objects. Quite apart from the restrictions of appetite of food, liquid, and sex objects, which are learned, hunger can be satisfied only by a restricted set of organic substances, thirst by a restricted set of liquids. Sexuality has a greater freedom of possible satisfiers since almost any object which is not too coarse in 
texture might be an adequate stimulus for stimulating the genitals, although the number of maximally satisfying possibilities is much more limited. The need for air is perhaps the most restricted in terms of the number of possible substitute gases. (Tomkins 1995, 59)

The erotic, what turns people on, is not only constituted, then, in relation to the zones, appendages, and orifices of the body that Freud so insightfully mapped and that Tomkins analyzes above but also, in turn, is activated and ultimately given meaning by wider social and historical transformations, in contextually variable ways.

To advance this argument, let me return to the last half of the nineteenth century. According to Arnold Davidson (1987), following Foucault ([1976] 1978), it was only then that the notion of sexuality was created. It did not exist before. And it was formed in the discourses of the sexologists we have already discussed. In sum, sexuality was and continues to be an assumed organization of individual psyches that produces (or is deflected from) reproductive sex. Types of perversions - homosexuality, fetishism, and sadomasochism-constitute their own distinctive forms, defined always by their structural opposition to reproductive heterosexuality.

The notion that every individual "has" a sexuality has grown more and more ingrained in European and North American thought. ${ }^{2}$ This notion can be seen in how titles of iconic works on sex have been translated into English. For example, the German title of Freud's famous work, first published in 1905, that we know now as Three Essays on the Theory of Sexuality was Drei Abhandlungen zur Sexualtheorie, or, as it was in fact first translated, Three Contributions to Sexual Theory. 
The adjective, "sexual," continually modifies and therefore moves, but the noun, "sexuality," denotes a determinate state of being with distinct predicates. The seemingly innocent transformation of an adjective into a noun tends to obscure, then, what Davidson specified as the genius of Freud in relation to the other sexual scientists, namely his blurring of the boundary between the normal and the abnormal. In perhaps the most famous footnote of the Three Essays, Freud ([1925] 2000, n. II) wrote: "Psycho-analytic research is most decidedly opposed to any attempt at separating off homosexuals from the rest of mankind as a group of a special character. By studying sexual excitations other than those that are manifestly displayed, it has found that all human beings are capable of making a homosexual object-choice and have in fact made one in their unconscious."

Today, Foucault's The History of Sexuality, Vol. I, has eclipsed Freud's text for many, but the irony of Foucault's title is apparently often lost (Jordan 2015). The grandiloquence of the title should have been the tip-off. The French subtitle, La volonté de savoir (The Will to Know), was dropped from the English translation and replaced by the anodyne An Introduction, but the French phrase captures Foucault's arguments more accurately. Indeed, the argument of Foucault's book is precisely to deconstruct the notion of sexuality, to show that it is an effect of the discourse created by the sexologists' will to know rather than any actually preexisting psychic, much less biological, condition.

Irony of ironies, then, that the sexual scientists' categories eventually got adopted, in what Foucault calls a "reverse discourse," by so-called deviants themselves. This is Foucault's doubly ironic account of "the history of sexuality" in the West. Given his enormous influence at present, it is altogether surprising to see his supposed followers pluralizing "sexuality" into 
"sexualities"-as an assumed progressive, more inclusive theoretical move.

I want to emphasize an implication of Foucault's argument that he himself did not explicitly draw out: ${ }^{3}$ that there must have been more same-sex sex before the notion of homosexuality than afterward. It is, of course, almost impossible to present data to back up such a claim. But Rocke's $(1996,5)$ study of records from Renaissance Florence is provocative: "In the later fifteenth century, the majority of local males at least once during their lifetimes were officially incriminated for engaging in homosexual relations."

And then there is the "naturally occurring experiment" of prisons in the United States. Regina Kunzel (2008) argues that straight prisoners indeed found erotic pleasure and even love with other men. ${ }^{4}$ She shows how the discourse on violent prison rape beginning in the 1960 s acted as a kind of screen against recognizing the deeply emotional bonds that existed between some men. Well into the twentieth century, prisons were organized by the opposition between "jockers" (who were straight) and "punks" (who were queer). But in practice, this opposition was continuously undermined. "San Quentin inmate and novelist Edward Bunker cited a 'jocular credo' that 'after one year behind walls it was permissible to kiss a kid or queen. After five years it was okay to jerk them off ... After ten years, "making tortillas" or "flip-flopping" was acceptable, and after twenty years anything was fine"" (Kunzel 2008, 185).

African men in the ghetto made these transitions rather more quickly. Or, more accurately, we might say that they faced no such "transition" in the first place? 